\title{
Sobre as revistas: Antropos; Baessler-Archiv; Ethnos; Folk; Provinzmagazin der Franziskaner von Nordbrasilien
}

\author{
Joachim G. Piepke* \\ Adriana Russi** \\ Astrid Kiefeer-Døssing *** \\ Marcos Antonio de Almeida**** \\ Roberto Soares de Oliveira ****
}

PIEKPE, J.G.; RUSSI, A.; Kiefeer-Døssing, A.; ALMEIDA, M.A.; OLIVEIRA, R.S.

Sobre as revistas: Antropos; Baessler-Archiv; Ethnos; Folk; Provinzmagazin der

Franziskaner von Nordbrasilien. R. Museu Arq. Etn. 37: 31-34, 2021.

Resumo: Neste capítulo do Dossiê, foram incorporados pequenos textos de diferentes autorias acerca das revistas e/ou jornais de divulgação científica que publicaram os originais em alemão que integram este volume, possibilitando uma contextualização mais profundada desses artigos.

Palavras-chave: Antropos; Baessler-Archiv; Ethnos; Folk; Provinzmagazin der Franziskaner von Nordbrasilien.

\section{O Instituto Anthropos e sua revista Anthropos ${ }^{1}$ \\ Por Joachim G. Piepke}

Anthropos é uma revista internacional de antropologia e linguística fundada em 1906 por Wilhelm Schmidt. Seu título é oriundo do grego $\alpha v \theta \rho \omega ́ \pi ı v o ~ o v$, que significa "ser humano", e expressa seu principal objetivo: trata-se de uma publicação dedicada aos estudos das sociedades humanas em sua dimensão cultural.

1 Sobre o Instituto e a Revista Anthropos, ver: http://www. anthropos.eu/anthropos/

* Instituto Anthropos. Missionário da Sociedade do Verbo Divino.<piepke@anthropos.eu>

** Docente da Universidade Federal Fluminense. Doutora em Memória Social pela Unirio. <adri.russitm@gmail.com> *** Doutoranda em Antropologia pela Aarhus Universitet (Dinamarca).<astridkieffer@gmail.com>

**** Membro do Arquivo Provincial Franciscano do Recife. <malmeida11@hotmail.com>

***** Diretor do Arquivo Provincial Franciscano do Recife. <noticiassantoantonio@gmail.com>
Antropologia, etnologia, linguística e estudos religiosos estavam no horizonte intelectual de Wilhelm Schmidt. Tal tradição se mantém até hoje pelos integrantes do Instituto Anthropos, responsável pela organização da revista.

O Instituto Anthropos foi fundado no dia $1^{\circ}$ de novembro de 1931, 25 anos depois da fundação da revista de mesmo nome, em St. Gabriel, próximo a Viena, pelo padre Wilhelm Schmidt, integrante da Congregação do Verbo Divino - Societas Verbi Divini (SVD). Quando as tropas alemãs ocuparam a Áustria, em 1938, o Instituto foi fechado pela Gestapo (Polícia Secreta Estatal) devido a sua resistência contra a ideologia racista do nazismo.

Com a ajuda do Cardeal de Viena e do Papa Pio XI, foi encontrada, em 1939, uma nova sede em Friburgo, Suíça. O instituto se mudou finalmente em 1962 para o espaço ocupado atualmente em St. Augustin, Alemanha, agregado à Faculdade de Teologia da SVD. 
Desde seus primeiros tempos, o Instituto Anthropos tem caráter próprio. Surgiu da necessidade de fornecer uma estrutura mais durável ao grupo da redação constituído ao redor do padre Schmidt e para dar continuidade a essa tarefa depois de sua aposentadoria. Os missionários foram, no início, os pesquisadores e fornecedores de material etnográfico. Aos poucos surgiu, mais e mais, a necessidade de formar pessoas dos próprios quadros da Congregação especializadas nas tarefas de pesquisa antropológica e de produção da Anthropos.

A ideia de Schmidt de pesquisar especialmente os povos mais originais do mundo (em alemão, die urvölker), supondo que entre eles seria encontrada a cultura mais original e, com ela, também a religião mais original -, o levou a enviar seus discípulos para os povos tidos àquela época como sendo os mais primitivos.

Na primavera de 1923, Schmidt estava em Roma ocupado com os preparativos de uma exposição missionária no Vaticano. Numa audiência com o papa Pio XI, ele expôs a urgência e a importância de estudos antropológicos entre aqueles povos. O papa respondeu então espontaneamente: "São documentos da humanidade que não devem se perder. Quando o senhor tiver concluído os preparativos para as expedições, retorne aqui. E se até lá a Divina Providência tiver fornecido meios suficientes, ajudar-lhe-ei" (Schmidt 1925: 719). De fato, o auxílio do papa permitiu que Schmidt realizasse quatro expedições.

Os membros do Instituto Anthropos são oriundos de diversas nações e pesquisam, publicam e ensinam em todo o mundo. O ponto principal não é mais a pesquisa entre os povos chamados originais, mas sim o estudo das mudanças culturais e religiosas em um mundo globalizado. Somente quatro dos atuais 44 membros do instituto residem na sede do Instituto, em St. Augustin. Os outros 40 têm suas tarefas nos diversos países em que atua a congregação: muitos são docentes em universidades, outros fundaram institutos próprios, como o Indian Institute of Cultures, de Mumbai e o Centre for Applied Cultural Research Sanskriti, de Indore (ambos na Índia); o Centre for the Study of Religion and Culture Candraditya, de Flores (Indonésia); o Melanesian Institute, de Goroka (Nova Guiné); o Tamale Institute of Cross-Cultural Studies, de Tamale (Gana); o Centre d'Études Ethnologiques, de Bandundu (Congo); e no momento, estuda-se a reativação do Instituto Anthropos do Brasil.

A temática das pesquisas varia de país a país e de região a região. Os membros contribuem para as publicações do instituto em St. Augustin e fazem suas pesquisas em diferentes continentes, mas projetos comuns como nos tempos de Schmidt não são mais viáveis. Ainda assim, prevalece até hoje a tarefa comum, já esboçada por ele, de buscar conhecer com maior profundidade as culturas e religiões do mundo para poder descobrir nelas as sementes da fé em Deus e de um mundo mais justo e fraterno.

O Instituto Anthropos resistiu até hoje a todas as tentativas externas de reorientação missiológica e continuará, no futuro, a seguir o caminho de sua herança antropológica. A estruturação atual da Igreja Católica, como também das igrejas protestantes tradicionais, está muito longe de poder ser considerada inserida nos povos do mundo. O hoje forçado processo de globalização, presente em todas as esferas da vida humana, exige urgentemente um reforço da identidade cultural dos povos e da diversidade das culturas. $\mathrm{O}$ tão desejado diálogo com as religiões e culturas só pode acontecer se as demais forem conhecidas e reconhecidas em suas particularidades. Eis aqui a tarefa futura dos antropólogos da SVD: resistir às tendências mundiais de uniformidade cultural e hegemonias inaceitáveis; resistir às tendências centralizadoras das igrejas ou de outras comunidades religiosas; abrir os olhos para os valores das tradições culturais; e acompanhar as mudanças inevitáveis. Essas serão, a meu ver, as quatro pedras angulares da Antropologia verbita.

\section{Baessler-Archiv: Beiträge zür Völkerkunde Por Adriana Russi e Astrid Kiefeer-Døssing}

A publicação Baessler-Archiv: Beiträge zür Völkerkunde (em português Arquivo Baessler: Contribuições para a Etnologia) recebeu apoio 
Joachim G. Piepke, Adriana Russi, Astrid Kiefeer-Døssing, Marcos Antonio de Almeida, Roberto Soares de Oliveira

financeiro da Fundação Baessler, criada em 1903, e leva o nome do viajante e pesquisador alemão Arthur Baessler (1857-1907).

Trata-se de uma revista alemã decorrente das publicações do Museu Real de Etnologia, que datavam desde 1889. Editada pelo Museu de Etnológico de Berlim, é voltada ao campo das contribuições etnológicas da instituição. O primeiro número foi publicado em 1910 e seguiu sequencialmente até o volume 25 , em 1943, quando houve uma interrupção durante o período da Segunda Guerra Mundial. Foi retomada em 1952, sendo publicada até hoje.

Os artigos são predominantemente em alemão, mas alguns também estão em outras línguas, como espanhol, inglês e francês. Ao longo dos anos, as contribuições para a revista focaram temas como povos indígenas, tradições, arte, museus e coleções e/ou cultura material - esta última por vezes associada aos objetos do Museu de Etnologia. Alguns números da revista podem ser acessados on-line.

\section{Ethnos}

\section{Por Adriana Russi e Astrid Kieffer-Døssing}

Ethnos é um jornal antropológico iniciado em 1936, quando o Museu Etnográfico de Estocolmo (Suécia) publicou seu primeiro volume. Em 1973, o periódico passou para o controle do Departamento de Antropologia Social da Universidade de Estocolmo. O jornal continua ativo, aceitando contribuições em ampla variedade de temas da antropologia e de outras disciplinas que contribuam para os interesses antropológicos. Atualmente, seus direitos autorais pertencem à Taylor \& Francis, que mantém todos os números acessiveis on-line.

\section{Folk}

\section{Por Astrid Kieffer-Døssing}

Em 1945, foi criada a disciplina de Antropologia na Universidade de Copenhagen. Na década seguinte, em 1959, houve a primeira reunião para a elaboração de um jornal dinamarquês anual sobre etnografia. A revista
Folk foi publicada pela Dansketnografisk

Forening (Sociedade Etnográfica

Dinamarquesa) entre 1959 e 2005 com artigos em inglês, alemão e francês.

Ao longo dos anos, os tópicos abordados refletiram o desenvolvimento dos debates antropológicos, temas de interesse de pesquisa e métodos dentro da disciplina na Dinamarca. No início, a revista e seus artigos estavam intimamente relacionados ao contexto dos museus, ao estudo do passado por meio da cultura material, com base em expedições e foco em culturas indígenas fora da Dinamarca. É desse período que datam os artigos sobre os povos indígenas Waiwai e Katxuyana, da América do Sul, escritos por Jens Yde, Niels Fock e Gottfried Polykrates

No início, muitos textos revista eram interdisciplinares, mas mudaram gradualmente à medida que o estudo acadêmico da antropologia a consolidou como campo de conhecimento na universidade. Como parte desse desenvolvimento, o escopo dos estudos também se afastou dos museus e da cultura material. No lugar, passaram a ser publicados artigos que abrangiam discussões do mundo moderno, como estudos de desenvolvimento, migração, antropologia médica e "antropologia em casa", com estudos de caso dentro da Dinamarca.

\section{A Provinzmagazin der Franziskaner von Nordbrasilien, ou Revista Santo Antônio Por Fr. Marcos Antonio de Almeida e Fr. Roberto Soares de Oliveira.}

\section{A Revista Santo Antônio, órgão de} comunicação da Província Franciscana do Brasil, foi criada para registrar as atividades missionárias e produções intelectuais dos frades franciscanos da Igreja Católica no Brasil. No início das ações evangelizadoras no vasto território do Nordeste do país, foi criada pelos frades alemães a gráfica Mensageiro da Fé. A experiência de imprimir alguns textos por iniciativa de Frei Jesualdo Machetti, em 1893, deu ânimo aos franciscanos de Salvador para ampliarem a produção. Nesse primeiro momento, foram impressas folhas avulsas e folhetos; em 1895, publicam uma 
Sobre as revistas: Antropos; Baessler-Archiv; Ethnos; Folk; Provinzmagazin der Franziskaner von Nordbrasilien R. Museu Arq. Etn., 37: 31-34, 2021.

obra mais volumosa de C. Clarindo Vicarius, com 39 páginas, intitulada Ordo Baptismi parvulorum aliaeque benedictionis valde utilis TAM missionariis quam sacerdotibus itinerantibus.

Os franciscanos alemães produziram textos para as aulas de teologia e áreas afins (espiritualidade, pastoral, missão, devoções, sociedade e outros temas pertinentes à Igreja e à sociedade). Nessa época, inauguram três livrarias para a venda de seus títulos. O convento de Salvador se dedicou por completo à instalação da gráfica São Francisco na Baixa do Sapateiro. Nessa mesma década, com a evolução da iniciativa empresarial de livros e impressos, a gráfica se tornou uma instituição não apenas do convento São Francisco de Salvador, mas de toda a província franciscana, que passou a administrar, nomear e dar as orientações técnicas e doutrinais às publicações. Uma de suas características era fazer chegar à sociedade as transformações sociorreligiosas por que passara o Brasil e seu povo (Bockey 1944).

A partir de 1924, foram assumidas novas orientações provinciais, e o empreendimento se adequava às exigências do mercado e às novas formas de gerenciamento. $\mathrm{O}$ desenrolar da história proporcionou a separação entre o convento e a gráfica, quando em 1940 esta passou a ser conduzida pela Província de Santo Antônio do Brasil. O convento de São Francisco cedeu o espaço físico e o maquinário, até então instalado em suas dependências. Com um embate entre a Província Franciscana e o governo do estado da Bahia, em 1940, a gráfica mudou seu estatuto de uma empresa religiosa para uma Sociedade Anônima, conforme as orientações de Artur Negreiros Falcão, advogado da Província.

Assim, em 16 de março de 1943, o Diário Oficial da Bahia, na página 1.817, informava sobre o "Contrato da Sociedade Editôra da Fé Ltda" como uma sociedade com fins comerciais. As orientações do governo do estado, fundamentadas na Constituição Federal, definem que a direção da empresa deverá ser assumida por um frade natural do Brasil, dando origem a uma nova etapa empresarial que continuou até os anos 1970, quando a sociedade deixou de atuar no ramo editorial.

PIEKPE, J.G.; RUSSI, A.; Kiefeer-Døssing, A.; ALMEIDA, M.A.; OLIVEIRA, R.S. About the journals: Anthropos; Baessler-Archiv; Ethnos; Folk; Provinzmagazin der Franziskaner von Nordbrasilien. R. Museu Arq. Etn. 37: 31-34, 2021.

Abstract: This chapter includes short texts from different authors about the scientific journals and/or newspapers that have published the German articles that form this Dossier, allowing for a better contextualization of them.

Keywords: Anthropos; Baessler-Archiv; Ethnos; Folk; Provinzmagazin der Franziskaner von Nordbrasilien.

\section{Referências bibliográficas}

Bockey, F.X. 1944. O cinquentenario da tipografia de São Francisco. Revista Santo Antônio 2:1828.

Kieffer-Døssing, A. 2016. Re-assembling the Katxuyana collections: an analysis of past, present and possible futures of the Katxuyana collections as assemblages. Dissertação de mestrado. Aarhus Universitet, Aarhus.
Schmidt, W. 1925. Die Forschungsexpedition von P.P. Schebesta, S.V.D., in 1924/1925 bei den Semang-Pygmäen und den Senoi-Pygmoiden auf der Halbinsel Malakka (British Malaya). Antropos 20: 718739. 